\title{
Practices of Jeddah Residents Regarding the Disposal of Unused and Expired Medications: A Community-Based Survey
}

\author{
Afnan A. Abuassonon 1', BSc, Bayader S. Kalkatawi ${ }^{1}$, BSc, Lamia S. Alzahrani ${ }^{1}$, BSc, \\ Basma G. Eid², PhD, and Thikryat A. Neamatallah², PhD \\ ${ }^{2}$ Department of Pharmacology and Toxicology, ${ }^{1}$ Faculty of Pharmacy, \\ King Abdulaziz University, Jeddah, Saudi Arabia
}

\section{Correspondence}

Dr. Thikryat Neamatallah

Department of Pharmacology

Faculty of Pharmacy

King Abdulaziz University

P.O. Box 80260, Jeddah 21589, Saudi Arabia

e.M: taneamatallah@kau.edu.sa

\section{Submission: 11 Feb. 2019}

Accepted: 21 Mar. 2019

\section{Citation}

Abuassonon AA, Kalkatawi BS, Alzahrani LS, Eid BG, Neamatallah T. Practices of Jeddah residents regarding the disposal of unused and expired medications: a community-based survey. JKAU Med Sci 2019; 26 (2): 35-44. DOl: 10.4197/Med.26-2.4

Copyright: (The Author(s), YEAR. Publisher. The Journal of King Abdualziz University - Medical Sciences is an Official Publication of "King Abdulaziz University". It is an open-access article distributed under the terms of the Creative Commons Attribution Non-Commercial License, which permit unrestricted non-commercial use, distribution, and reproduction in any medium, provided the original work is properly cited.

\begin{abstract}
Inappropriate disposal of stored medications leads to an increased risk of environmental toxicity. This study aims to examine practices of Jeddah residents with regard to disposing unused and/or expired medications and to view their opinions about the presence of drug take-back centres. Over a 3-month period, 771 participants completed an online questionnaire, that focused on disposal methods and the importance of having drug retrieval centres. The data demonstrated that $91.57 \%$ of the participants reported discarding their expired medications in household waste, and $2.98 \%$ of them return their medications to hospitals or pharmacies. With respect to unused medications, $67.07 \%$ of the participants disposed of them in household waste, and only $10.84 \%$ donated their medications. This improper practice, however, contradicted the fact that $92.35 \%$ of the respondents were interested in knowing the appropriate methods of disposing. In addition, $90.66 \%$ agreed to the need for drug take-back centres. Our study demonstrated that a low percentage of respondents knew about correct medication disposal. This emphasizes the need for the Ministry of Health, the pharmaceutical industry and pharmacies to collaborate on a national program about the proper methods of medication disposal and to initiate drug retrieval programs.
\end{abstract}

\section{Keywords}

Expired medications; Unused medications; Saudi Arabia; Disposal

\section{Introduction}

0 ver the past several years, a great increase in the use of pharmaceutical products has occurred worldwide. This global increase in the use of these substances has brought attention to the negative impacts of improper disposal of these materials on the environment ${ }^{[1,2]}$. For example, disposing of medications in sinks or by flushing them down toilets ultimately causes significant environmental risk particularly the poisoning of waterways, which may affect marine life and cause harm to people and animals $s^{[1,3]}$. The active compound of oral contraceptive, ethinyl estradiol, found in waterways has been shown to cause sexual disruption in wild fish populations ${ }^{[4]}$. There is also evidence that the traces of antibiotics in the aquatic 
environment has an impact on the bacteria present and may lead to increased antibiotic resistance ${ }^{[5]}$. Many people are unaware of the proper methods for disposal of unused or expired medications, and a there exists a great need to spread awareness of the matter to the general population.

Several factors could lead to a surplus of medications in the household, including intentional or accidental patient noncompliance due to speedy recovery before completing the prescribed treatment and medications being stopped or changed due to side effects or ineffectiveness ${ }^{[6]}$. According to the World Health Organization (WHO), half of patients fail to take medicine correctly and greater than $50 \%$ of all medications are improperly prescribed and sold, all of which ultimately causes unnecessary storage of these medications ${ }^{[7]}$. Looking at Saudi Arabia in particular, the governmental health care system provides free medication to the population and many people have insurance coverage ${ }^{[8]}$, which may therefore lead to the accumulation of medications in the household.

To reduce improper medication disposal, countries like the United States have initiated pharmaceutical collection programs that educate society about the health consequences and environmental impact of inappropriate medication disposal, as well as decrease the quantity of unused and expired medications[9]. Other developed countries such as Canada, the United Kingdom and Sweden have also established drug take back sites to avoid this environmental risk, which is considered the proper method for disposal of medications. After drugs collection, the final common method of rendering pharmaceutical substances unusable is by incineration ${ }^{[10-14]}$.

Studies were conducted in Saudi Arabia such as in Riyadh, Qassim and the Western region that evaluated public awareness regarding medication disposal ${ }^{[8,15,16]}$. Particularly in Jeddah, the authors aimed to evaluate participants' personal practices regarding the disposal of expired and/or unused medication. Moreover, the study was conducted to view their opinions about the presence of drug take-back centers in Saudi Arabia.

\section{Methods}

An online survey targeting people in Jeddah, Saudi Arabia, was carried out based on a structured questionnaire format (Appendix 1). The English questionnaire was validated by two expert researchers from Faculty of Pharmacy, King Abdulaziz University. Then, the final English draft of the questionnaire was translated into Arabic and reviewed by two researchers. A pilot test was performed on 12 respondents for survey consistency. The minimum recommended size of our survey was 385 using confidence level of $95 \%$, response distribution of $50 \%$ and a margin error of $5 \%$. With 771 respondents, the margin error decreased to $3.53 \%$.

The questionnaire included closed ended questions such as "Yes" or "No" response questions or multiple-choice questions. Multiple-choice responses with an option to specify different answers as a last choice provided respondents with the opportunity to answer in their own way and to add responses, which were not listed previously. These added answers were revised and grouped into a common theme. The survey was performed using the web-based survey software qualtrics $\mathrm{XM}^{\circ}$ available on https://www.qualtrics.com. Graphs were sketched using Microsoft Excel, 2013 (Microsoft Corp., Redmond, WA, USA) and Prism6, version 6 (GraphPad Software, San Diego, CA, USA).

The questionnaire elicited socio-demographic data from respondents, the use of medications and their practices with regard to medication disposal. The questionnaire also examined information from respondents on the best method of disposal of unused and expired medications and the responsible bodies for collecting these types of medications. Respondents were also questioned about the importance of proper methods of disposing the medications. The survey was conducted from February 2018 to April 2018. The study design was reviewed and approved by the Unit of Biomedical Ethics Research Committee at King Abdulaziz University (1438-102).

\section{Results}

Over a period of three months, a total of 771 complete responses out of (802) were received from residents of Jeddah, including 533 females (69.08\%) and 238 males $(30.92 \%)$, with an overall response rate $(96.0 \%)$. Most of the respondents were between the ages of 20-30 years $(36.91 \%)$ and were at least undergraduate educated $(69.70 \%)$ (Table 1). About half of the respondents $(55.87 \%)$ stated having stored medications at home (72.0\% of these medications were prescribed, $24.5 \%$ were non-prescribed medications and 3.5\% both). 
Table 1. Demographic data of the respondents.

\begin{tabular}{|l|c|c|}
\hline \multicolumn{1}{|c|}{ Characteristics } & Parameter & $\mathbf{7 7 1}(\%)$ \\
\hline \multirow{2}{*}{ Gender } & Male & $238(30.92 \%)$ \\
& Female & $533(69.08 \%)$ \\
\hline Age (years) & $\leq 20$ & $62(7.98 \%)$ \\
& $21-30$ & $285(36.91 \%)$ \\
& $31-40$ & $175(22.69 \%)$ \\
& $41-50$ & $145(18.83 \%)$ \\
Education Level & 51 and above & $104(13.59 \%)$ \\
& Pre-secondary & $21(2.74 \%)$ \\
& Secondary & $121(15.71 \%)$ \\
& Undergraduate & $537(69.70 \%)$ \\
& Postgraduate & $85(10.97 \%)$ \\
\end{tabular}

Table 2. Types and sources of stored medications.

\begin{tabular}{|c|c|}
\hline \multicolumn{2}{|l|}{ Stored Medications } \\
\hline Answer & $771(\%)$ \\
\hline Yes & $431(55.87 \%)$ \\
\hline No & $340(44.13 \%)$ \\
\hline \multicolumn{2}{|c|}{ Types of Stored Medication } \\
\hline Type & $431(\%)$ \\
\hline Prescription & $310(72.00 \%)$ \\
\hline Non-Prescription & $106(24.50 \%)$ \\
\hline Both & $15(3.50 \%)$ \\
\hline \multicolumn{2}{|c|}{ Source of Prescribed Medications } \\
\hline Source & $325(\%)$ \\
\hline Government & $81(24.81 \%)$ \\
\hline Insurance & $86(26.56 \%)$ \\
\hline Purchased & $158(48.63 \%)$ \\
\hline
\end{tabular}

Prescribed medications were supplied free of charge in the case of medically insured patients or purchased from private pharmacies (Table 2).

In response to the types of stored medications, respondents used to store over the counter (OTC) pain medications (33.2\%), flu medications (28.38\%), vitamins and supplements (15.7\%), topical medications (12.89\%), medications for chronic diseases (7.9\%) and others $(1.93 \%)$ such as acne medication and gastric discomfort medications (Fig. 1).

Furthermore, respondents were questioned about monitoring and usage habits of the stored medications. The majority of the respondents regularly check medication expiry date (87\%), few of them do not usually check (9\%) and only $4 \%$ never check medication expiry (Fig. 2). Surprisingly, about $56 \%$ of the respondents replied having stored medication in new condition and $44 \%$ benefited from their stored medications.
Concerning the disposal of expired medications, most of the respondents (91.57\%) reported discarding their expired medications in the household garbage, while $2.98 \%$ of them return medications to hospitals or pharmacies. Only $1.43 \%$ of respondents flush medications down the toilets, $1.69 \%$ afford them to friends and relatives and $2.33 \%$ stated other answers such as donations to charity institutions (Fig. 3). On the other hand, when looking at disposal of unused medications, it was found that unused medications were disposed in the household garbage (67.07\%), given to friends or relatives $(18.47 \%)$, or donated $(10.84 \%)$ to various associations and charities. Only $1.61 \%$ stated they return their medications to pharmacies and hospitals and $2.01 \%$ of the respondents discard the medication down the toilets (Fig. 4).

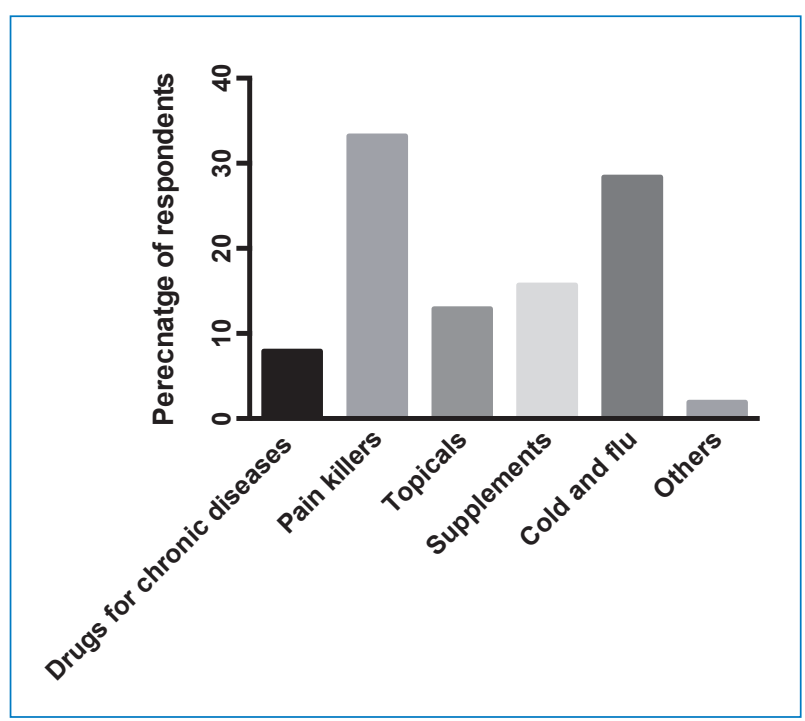

Figure 1. Classes of stored medication. 


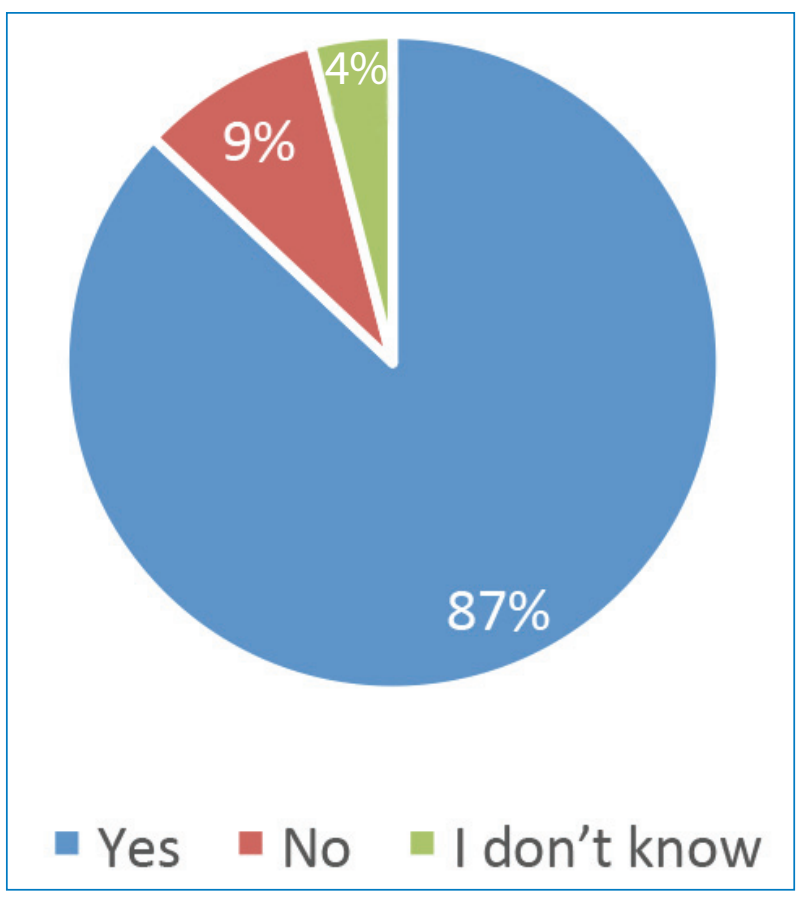

Figure 2. Respondent's practices on expiry date follow-up.

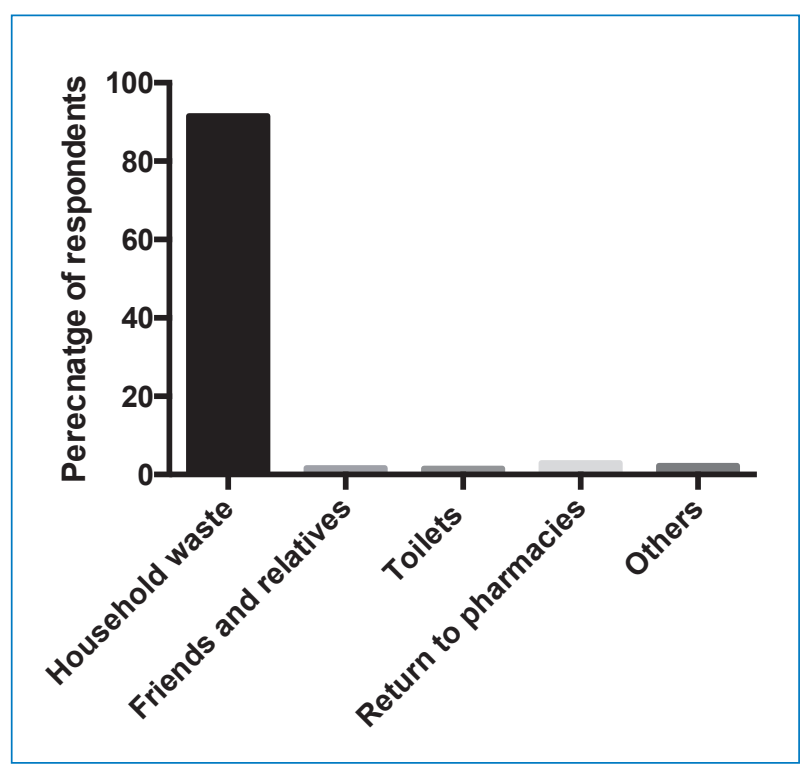

Figure 3. Disposal methods of expired medications.

Moreover, respondents' opinions on the importance of using appropriate medication disposal methods was evaluated. About $92.35 \%$ of respondents agreed that medications should be correctly disposed of, while only $7.65 \%$ were incurious. In addition, $75.62 \%$ agreed that inappropriate medication disposal can

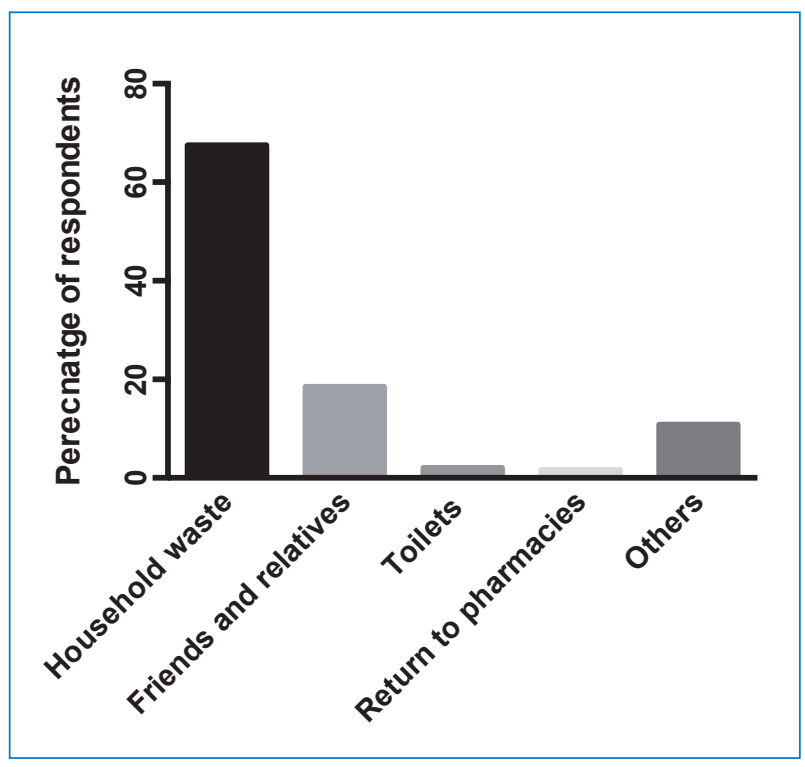

Figure 4. Disposal methods of unused medications.

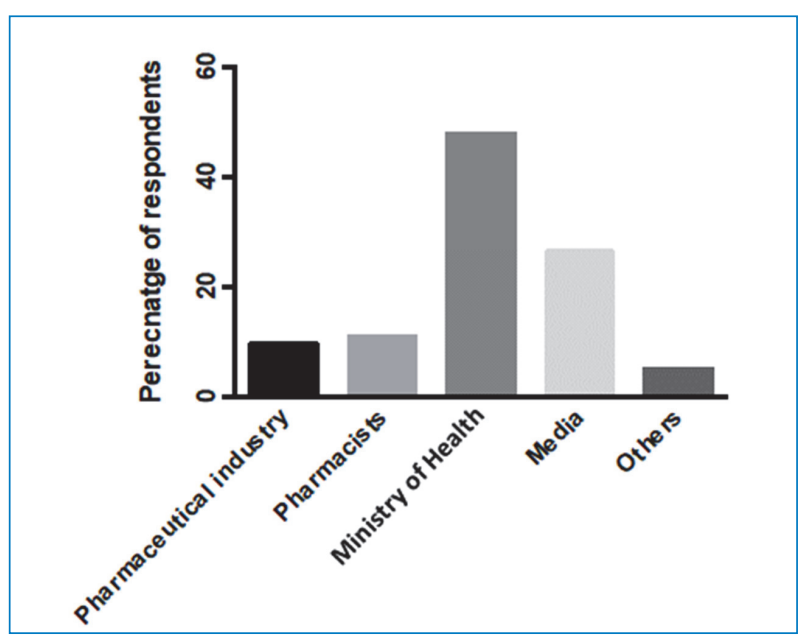

Figure 5. Responsible bodies for medication disposal awareness.

negatively affect the health and environment. Whereas, $3.11 \%$ found it is not harmful and $21.27 \%$ were not sure about the hazards of improper medication disposal (Table 3).

Finally, respondents displayed their opinion regarding the responsible awareness bodies (Fig. 5). About half of the respondents $47.99 \%$ believed it is the Ministry of Health's role. Whereas, $9.6 \%$ of the answers proposed that it is the pharmaceutical industry's responsibility to raise awareness programs. Similarly, $10.89 \%$ believed it is the pharmacist's job and $26.46 \%$ 
Practices of Jeddah Residents Regarding the Disposal of Unused and Expired Medications: A Community-Based Survey $A A$. Abuassonon et al.

Table 3. Awareness of disposal medications.

\begin{tabular}{|l|c|c|c|}
\cline { 2 - 4 } \multicolumn{1}{c|}{} & Yes & No & I Do Not know \\
\hline Is it important to use the right method for medications disposal? & $92.35 \%(\mathrm{~N}=712)$ & $7.65 \%(\mathrm{~N}=59)$ & 0 \\
\hline Dose improper medications disposal negatively affect the health and environment. & $75.62 \%(\mathrm{~N}=583)$ & $3.11 \%(\mathrm{~N}=24)$ & $21.27 \%(\mathrm{~N}=164)$ \\
\hline
\end{tabular}

Table 4. Opinions on initiating drug retrieval centers.

\begin{tabular}{|l|c|c|c|}
\cline { 2 - 3 } \multicolumn{1}{c|}{} & Yes & No & I don't know \\
\hline Do you support the presence of drug retrieval center for unused medications? & $90.66 \%$ & $5.06 \%$ & $4.28 \%$ \\
\hline
\end{tabular}

selected audiovisual media \& social media and only $5.06 \%$ chose other options such as hospitals.

At the end of the survey, respondents were asked if they supported the presence of medication take back centers. It was found that $90.66 \%$ of responders supported the idea, while $5.06 \%$ disagreed and $4.28 \%$ were not sure about the correct answer (Table 4). This suggests their interest in implementing a proper drug disposal system.

\section{Discussion}

This study examined Jeddah society's awareness regarding the disposal of expired and unused medications by surveying 771 individuals in Jeddah over a period of three months. In addition, it evaluated participants' interest in establishing drug takeback centers. The majority of the respondents were educated females between the ages of 20-30, which could be a limitation of the study. About half of the respondents affirmed that $72 \%$ of the medications they stored were prescribed by doctors, suggesting medical illnesses that require consultation are common in people of this group. The rest of the stored drugs (24.5\%) were non-prescribed drugs, which might point to improper purchasing, accumulation and storing. Similar studies conducted in other countries agree that most respondents' medications are obtained by prescriptions, whereas fewer people purchase their medications without prescriptions $\mathbf{s}^{[10,12,13]}$.

In the current study, prescribed medicines were mostly purchased (48.63\%), while $24.81 \%$ and $26.56 \%$ were governmentally supplied and medically insured, respectively. Thus, half of the prescribed medicines were obtained for free, which further indicates accumulation of medication and inappropriate storage were possibly due to large quantities of dispensed medications that generally exceeded the treatment period. Looking at the types of stored medicines, over-the-counter drugs, especially painkillers, had the highest percentage, whereas medications used to treat chronic diseases were stored the least, suggesting the respondents' compliance with these medications. These results are comparable to a study conducted in Mexico that reported most stored medications were pain killers, specifically non-steroidal anti-inflammatory drugs (NSAIDs) $^{[1,12]}$.

The respondents' practices regarding stored medicines in this study indicated that the majority inspect their medication expiry dates regularly, which directly reflects their educational level. However, discarding medication in a bin represented the main disposal method, which coincides with other countries such as the United States, Australia, Mexico and Kuwait ${ }^{[1,12,13,17]}$. This reflects the lack of awareness of the hazards this method presents to people's health and the environment, including aquatic pollution and the threat of misuse ${ }^{[18,19]}$. A very low percentage of respondents ( $2.33 \%$ and $10.84 \%$, respectively) who either donate their expired and/or unused medication to hospitals and charity centers in Jeddah (e.g., www. zmzm.org) suggested their willing to return left over drugs instead of randomly disposing them.

On the other hand, the majority of the respondents showed their interest in learning the proper methods for medication disposal. Specifically, most of them supported the presence of drug take-back centers to solve this issue. Lubick ${ }^{[19]}$ reported that pharmaceutical take-back programs could make a difference in protecting the environment from pharmaceutical toxicities. Lubick ${ }^{[19]}$ cited an example in Maine, USA, in which authorities announced in 2009 that industries are required to establish take-back programs for 
Practices of Jeddah Residents Regarding the Disposal of Unused and Expired Medications: A Community-Based Survey $A A$. Abuassonon et al.

unused pharmaceuticals. The authorities also called for pharmacies to provide envelopes to customers to mail unused pharmaceuticals back to the manufacturer.

Although the Ministry of Health has started to monitor and limit the inappropriate purchase of prescription drugs without an actual prescription, no specific regulations address medication disposal, which would ultimately decrease storing unnecessary medications ${ }^{[20]}$. Moreover, no specific programs and/or regulations on methods of medication disposal exist. In agreement with a recent study conducted in Riyadh ${ }^{[16],}$ a low number of people have received information regarding correct medication disposal methods, suggesting that comprehensive drug disposal policies with drug take-back programs are in definite need in Saudi Arabia. However, due to unavailability of drug take back locations, or programs, the U.S. Food and Drug Administration listed a guide that can be followed to dispose of medicines at home. The U.S. Food and Drug Administration recommends to mix medicines with an unappealing substance in a container sealed in plastic bags, which can then be discarded in the trash. This step can be acknowledged as a temporary solution until other proper options for disposing of medicines are developed ${ }^{[21]}$.

\section{Conclusion}

This study highlights the need to raise awareness in Jeddah, Saudi Arabia regarding the proper methods of medication disposal. Furthermore, a great need exists to initiate comprehensive drug disposal policies and pharmacies with drug take-back programs. This would greatly reduce the associated hazards of improper medication disposal and improve the quality of life of patients across Saudi Arabia.

\section{Conflict of Interest}

The authors have no conflict of interest.

\section{Disclosure}

The authors did not receive any type of commercial support either in forms of compensation or financial for this study. The authors have no financial interest in any of the products or devices, or drugs mentioned in this article.

\section{Ethical Approval}

The study design (Ref. No. 1438-105) was reviewed and approved, by the Unit of Biomedical Ethics Research Committee at King Abdulaziz University.

\section{References}

[1] Bergen PJ, Hussainy SY, George J, Kong DC, Kirkpatrick CM. Safe disposal of prescribed medicines. Aust Prescr 2015; 38(3): 90-92.

[2] Azad, MAK, Ansary MRH, Akber MA, Al-Mamun SMM, Uddin M, Rahman MM. Disposal practice for unused medications among the students of the International Islamic University Malaysia. J Appl Pharma Sci 2012; 02(7): 101-106.

[3] Daughton CG. Cradle-to-cradle stewardship of drugs for minimizing their environmental disposition while promoting human health. I. Rationale for and avenues toward a green pharmacy. Environ Health Perspect 2003; 111(5): 757-774.

[4] Jobling S, Williams R, Johnson A, Taylor A, Gross-Sorokin M, Nolan M, Tyler CR, van Aerle R, Santos E, Brighty G. Predicted exposures to steroid estrogens in U.K. rivers correlate with widespread sexual disruption in wild fish populations. Environ Health Perspect 2006; 114 Suppl 1: 32-39.

[5] Costanzo SD, Murby J, Bates J. Ecosystem response to antibiotics entering the aquatic environment. Mar Pollut Bull 2005; 51(1-4): 218-223.

[6] Pore SM. Pharmaceutical waste from hospitals and homes: need for better strategies. Indian J Pharmacol 2014; 46(4): 459-460.

[7] [No authors listed]. Essential Medicines and Health Products Information Portal. A World Health Organization resource. Challenges in expanding access to essential medicines. Accessed October 29, 2018. <http://apps.who. int/medicinedocs/en/d/Js5571e/2.html>.

[8] AlAzmi A, AlHamdan H, Abualezz R, Bahadig F, Abonofal N, Osman M. Patients' knowledge and attitude toward the disposal of medications. J Pharm (Cairo) 2017; 2017: 8516741

[9] Glassmeyer ST, Hinchey EK, Boehme SE, Daughton CG, Ruhoy IS, Conerly O, Daniels RL, Lauer L, McCarthy M, Nettesheim TG, Sykes K, Thompson VG. Disposal practices for unwanted residential medications in the United States. Environ Int 2009; 35(3): 566-572.

[10] Tong AY, Peake BM, Braund R. Disposal practices for unused medications around the world. Environ Int, 2011; 37(1): 292-298.

[11] Persson M1, Sabelström E, Gunnarsson B. Handling of unused prescription drugs--knowledge, behaviour and attitude among Swedish people. Environ Int 2009; 35(5): 771-774. 
[12] Gracia-Vásquez SL, Ramírez-Lara E, Camacho-Mora IA, Cantú-Cárdenas LG, Gracia-Vásquez YA, Esquivel-Ferriño PC, Ramírez-Cabrera MA, Gonzalez-Barranco P. An analysis of unused and expired medications in Mexican households. Int J Clin Pharm 2015; 37(1): 121-126.

[13] Abahussain EA, Ball DE, Matowe WC. Practice and opinion towards disposal of unused medication in Kuwait. Med Princ Pract 2006; 15(5): 352-357.

[14] Abruquah AA, Drewry JA, Ampratwum FT. What happens to unused, expired and unwanted medications? A survey of a community-based medication disposal practices. Int J Dev Sust 2014; 3(12): 2175-2185.

[15] Abdallah QM, Al-Haddad MS, Al-Khathami OH, Al-Kherish $\mathrm{OH}$, Al-Marri KM, Al-Matani MF, Al-Rashed AM. Knowledge, attitude and practice towards discarding unwanted household medicines among university students in Western region, KSA. Int J Pharma 2014; 4(4): 14-21.

[16] Al-Shareef F, El-Asrar SA, Al-Bakr L, Al-Amro M, Alqahtani F, Aleanizy F, Al-Rashood S. Investigating the disposal of expired and unused medication in Riyadh, Saudi Arabia: a cross-sectional study. Int J Clin Pharm 2016; 38(4): 822-828.

[17] Seehusen DA, Edwards J. Patient Practices and Beliefs Concerning Disposal of Medications. J Am Board Fam Med 2006; 19(6): 542-547.

[18] Corcoran J, Winter MJ, Tyler CR. Pharmaceuticals in the aquatic environment: A critical review of the evidence for health effects in fish. Crit Rev Toxicol 2010; 40(4): 287-304.

[19] Lubick N. Drugs in the environment: do pharmaceutical take-back programs make a difference? Environ Health Perspect 2010; 118(5): A210-A214.

[20] [No authors listed]. Ministry of Health $(\mathrm{MOH})$ warns against selling antibiotics without prescription. WHO NEWS. Accessed April 17, 2018. from <https://www.moh.gov.sa/ en/Ministry/MediaCenter/News/Pages/news-2018-04-17004.aspx>.

[21] [No authors listed]. Drug disposal: dispose "non-flush list" medicine in trash. FDA. 2018. Accessed April 2, 2019. < https://www.fda.gov/drugs/disposal-unused-medicineswhat-you-should-know/drug-disposal-dispose-non-flushlist-medicine-trash>. 
Appendix 1. Questionnaire Form.

\section{Practices of Jeddah Residents Regarding the Disposal of Unused and Expired Medications}

\section{Background Information}

\section{1-Gender:}
1. Male
2. Female

2-Age:

1. $\leq 20$

2. $21-30$

3. $31-40$

4. $41-50$

5. 51 and above

3-Educational level:
1. None
2. Pre-secondary
3. Secondary
4. undergraduate
5. Postgraduate

Q1: Do you have any stored medications at home?
1. Yes
2. No

Q2: What are the types of your stored medications?
1. Prescription medication
2. Non-prescription medication
3. Both

Q3: How do you receive your prescribed medications?
1. Free of charge from governmental pharmacies
2. Free of charge from private pharmacies (for patients with medical insurance)
3. I purchase my medications from private pharmacies

Q4: What are the classes of your stored medications?
1. Cold and flu medications
2. Pain killers
3. Vitamins and supplements
4. Topical medications
5. Medication for chronic disease such as hypertension and diabetes..etc
6. Others

Q5: Do you regularly check the expiry date of your stored medications?
1. Yes
2. No
3. I don't know what expiry date means. 
Appendix 1. (Continuation) Questionnaire Form.

Q6: How do you dispose your expired medications?

1. In the household garbage

2. Down the toilet

3. I give them to friends or relatives

4. I return them to the hospitals or pharmacies

5. Others

Q7: Do you have any unused stored medications?

1. Yes

2. No

Q8: How do you dispose your unused medications?

1. In the household garbage

2. Down the toilet

3. I give them to friends or relatives

4. I return them to the hospitals or pharmacies

5. Others

Q9: Can inappropriate medications disposal methods affect the health and the environment?
1. Yes
2. No
3. I don't know

Q10: Is it important to use the right method for medications disposal?
1. Yes
2. No
3. I don't know

Q11: Who do you think is responsible for society awareness regarding the proper methods of medications disposal?

1. The pharmaceutical industry

2. Pharmacists

3. Ministry of health

4. Audiovisual media \& social media

5. Others

Q12: Do you support the presence of drug take-back centers for excess unused or expired medications?

1. Yes

2. No

3. I don't know 


\section{ممارسات سكان جدة فيما يتعلق بالتخلص من الأدوية غير المستخدمة والمنتهية الصلاحية: مسح مجتمعي}

أفنان علي أبو السنون' ، وبيادر صلاح كلكتاوي'، ولمياء سعيد الزهراني'، ويسمة غازي عيدّ،

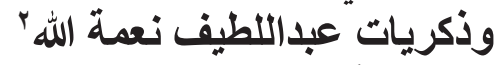

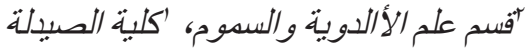

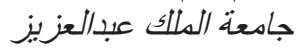
جلة ـ المعلكة العربية السعودية

المستخلص. التخلص من الأدوية يؤدي إلى زيادة خطر السمية البيئة. الهدف من هذه الدراسة هو فحص ممارسات سكان

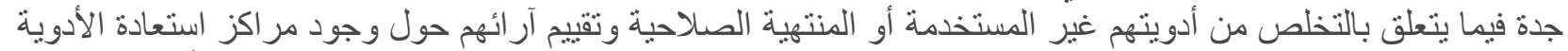

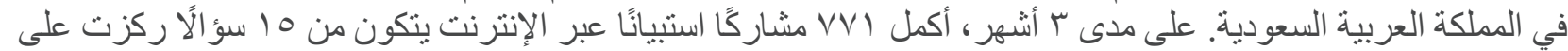

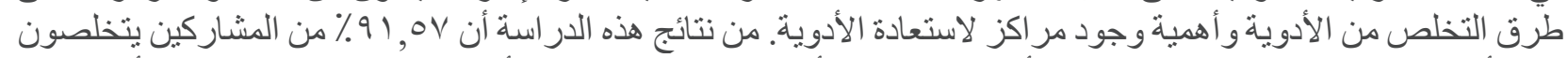

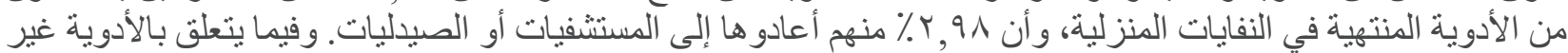

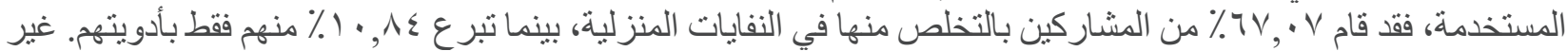

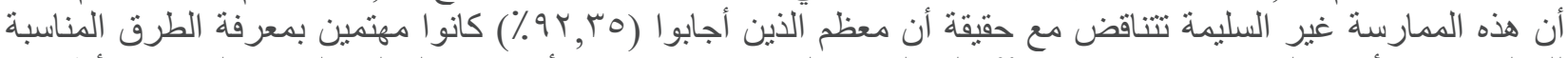

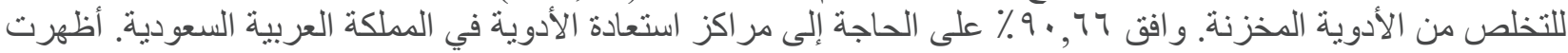

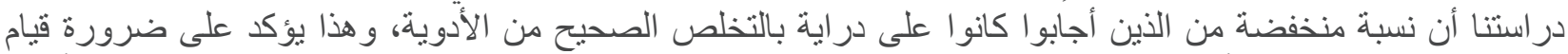

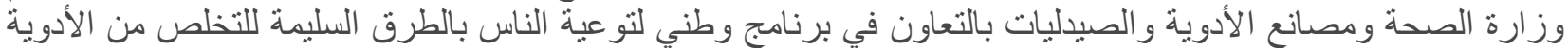

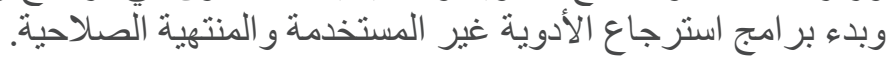

